\title{
A PRELIMINARY MECHANICAL DESIGN EVALUATION OF THE WIKISPEED CAR: FOR LIGHT-WEIGHTING IMPLICATIONS
}

\begin{abstract}
Purpose: Road passenger transportation faces a global challenge of reducing environmental pollution and greenhouse gas emissions due to vehicle weight increases needed to enhance passenger safety and comfort. This paper presents a preliminary mechanical design evaluation of the Wikispeed Car (with a focus on body bending, body torsion and body crash) to assess light-weighting implications and improve the vehicle's environmental performance without compromising safety.
\end{abstract}

Approach: For this research, finite element analysis (FEA) were performed to examine the Wikispeed chassis for light-weighting opportunities in three key aspects of the vehicle's design, namely: i) for body bending the rockers (or longitudinal tubes); ii) for body torsion (again on the rockers but also the chassis as a whole); and iii) for crash safety - on the frontal crash structure. A two phase approach was adopted, namely: in phase one, a 3D CAD geometry was generated; and in phase two FEA was generated. The combination of analysis results was used to develop the virtual model using FEA tools and the model was updated based on the correlation process.

Findings: The research revealed that changing the specified material Aluminium Alloy 6061T651 to Magnesium EN-MB10020 allows vehicle mass to be reduced by an estimated $110 \mathrm{~kg}$, thus, producing a concomitant $10 \%$ improvement in fuel economy. The initial results imply that the current beam design made from magnesium would perform worst during a crash as the force required to buckle the beam is the lowest (between $95.2 \mathrm{kN}$ and $134 \mathrm{kN}$ ). Steel has the largest bandwidth of force required for buckling and also requires the largest force for buckling (between $317 \mathrm{kN}$ and $540 \mathrm{kN}$ ).

Originality: This is the first study of its kind to compare and contrast between material substitution and its impact upon Wikispeed car safety and performance.

\section{KEYWORDS}

Finite element analysis, light-weight materials, emission reduction, greenhouse gas emissions, Wikispeed Car. 


\section{INTRODUCTION}

Tougher regulatory requirements intended to control greenhouse gas emissions from vehicles have prompted manufacturers to be technologically innovative in both the design and manufacture of their cars. Of the various options available, vehicle weight reduction remains a prominent and viable option (Harvey, 2018). Specifically, the use of lightweight materials to replace conventional steel in passenger vehicles with internal combustion engines (ICE) has gained noteworthy attention (Luk et al., 2017). This is because lightweight materials substitution can help to reduce fuel consumption and the formation of exhaust emissions (AlSabbagh et al., 2017; Fernández, 2018; Luján et al., 2018). Of the various design options available, the greatest opportunity to reduce vehicle weight comes from the body structure whilst further weight reductions can be achieved by downsizing other compartments such as the engine; where a compartment represents a major section of a vehicle (e.g. engine, transmission, body structure) that contains numerous components (Shi et al., 2007).

A widely acclaimed design innovation is the Wikispeed car that was developed as an opensource project founded in 2006 by Joe Justice (Kostakis et al., 2015). The project sought to create an ultra-lightweight, ultra-fuel-efficient and affordable 'roadster car' that is fun, fast and pleasurable to drive. The Wikispeed car evolved from an eco-challenge racing car which has meant that luxury has been forsaken for a lightweight sports car without a roof, lockable trunk and doors (Socha et al., 2013). The Wikispeed can accelerate from 0 to 60 miles per hour (mph) in less than 5 seconds, has a top speed of $140 \mathrm{mph}$, weighs 1,404 imperial pounds and is capable of 100 miles per gallon (mpg).

Against this contextual backdrop of progressive engineering design to solve real-world problems, this paper investigates the structural and safety performance of the Wikispeed car in terms of bending stiffness, torsional stiffness, and crashworthiness (through analytical calculations). The structural elements of the Wikispeed car are critically analysed using ANSYS FEA software and the results and findings of light-weight substitution opportunities are discussed. The research concludes with design recommendations that could enhance the environmental performance of the car without unduly compromising passenger safety.

\section{LIGHTWEIGHT MATERIALS AND THEIR APPLICATIONS}

Sustainable design in the early phases of new passenger vehicle development has gained paramount importance within both society and the automotive industry business over recent 
decades (Grey and Tarascon, 2017). Innovative concepts such as the use of lightweight material design and crashworthiness have consequently gained prominent attention for their high strength, stiffness and high energy absorption capabilities (Pradeep et al., 2017). In the initial product development phases, designers and engineers must consider material selection to accurately establish lightweight and durability parameters (Danilecki et al., 2017). Another concomitant objective being to present a structural analysis of lightweight components selected - to enhance mass reduction, reduce greenhouse gas emissions and in so doing, decrease energy consumption (Xiong et al., 2018).

Both the extant literature and manufacturer literature are replete with examples of vehicle light-weighting studies and the benefits of these. Traditionally, low density materials such as aluminium, steel, magnesium and composite materials have been prominently used in the automobile industry to replace ferrous alloys (Barton and Fieldhouse, 2018). Higher strength, ductility is provided by ferrous alloys at a lower cost when compared to low density alloys (Melado et al., 2017). High strength to weight ratio is provided by ultra-high strength cast alloys - such materials properties produce structural components for passenger car vehicles (especially for the production of thinner wall section thus decreasing the overall weight of the component) (Mohrbacher, 2013). For example, Figure 1 illustrates that increasing the yield strength of steel from $200 \mathrm{MPa}$ to $550 \mathrm{MPa}$ a typical structural component weight is reduced by approximately $62.5 \%$ under different load cases.

\section{<Insert Figure 1 about here>}

However, from a historical perspective and without changing the interior volumes of passenger cars, the average vehicle weight increased by approximately $118 \mathrm{~kg}$ between 1995 to 2010, and since 2010 vehicle weight has remained constant (Joost and Krajewski, 2017). More recently, aluminium sheet was used to manufacture the 2015 Ford 150 body structure and closure panels, whereas the Cadilac ATS and CT6 used high strength steel and aluminium extrusions (Tang, 2017). From 2006 to 2013, the Chevrolet Corvette Z06 cradle was made out magnesium, albeit it also showcased an aluminium hydro formed structure which was a variant to Corvette base which was made out of steel (Taub and Luo, 2015). A key material substitution of magnesium to aluminium enabled: weight reduction at the front of the vehicle; galvanic corrosion reduction; and achieved the same stiffness. Another application of lightweight materials (i.e. magnesium) was for instrument panels or cross bar 
beams that were traditionally made out of steel stampings prior to 2000's (Taub et al., 2007). General Motors, also generated high volumes of magnesium made instrument panels for their cars during the period 2005 to 2006 (Hong and Shin, 2017). Post 2010 and the global economic crisis, the usage of magnesium instruments drastically fell due to rising pricing, which resulted in the development of tubular steel designs to reduce overall vehicle weight (Sasanka and Kumar, 2017). In 2012, the Cadillac STS manufactured an aluminium deck lid (and magnesium inner parts with outer coating of aluminium) using General Motor's quick plastic forming (QPF) technology (Luo et al., 2016). This design innovation increased mass savings of $1.5 \mathrm{~kg}$ for the deck lid as compared to previous versions (Muthuraj et al., 2017). While conducting a life cycle assessment, Koltun et al., (2016) performed a sensitivity analysis and demonstrated that significant mass reduction of components can be readily achieved by using Australian magnesium vis-a-vis standard US aluminium. To illustrate light-weighting effects, Ding et al. (2016) conducted a sensitivity analysis study to show different energy savings on automobile parts in China by replacing them with aluminium. Results recorded over a vehicle life cycle of 200,000 km driving revealed that when typical steel parts were replaced with aluminium parts, the vehicle consumed 1,447 to 1,590 litres less gasoline. A tailored model to assess the environmental benefits of light-weighting on diesel turbocharged vehicles was presented by Delogu et al., (2016) and was based upon fuel reduction value (FRV). Their results (ibid) showed that the FRV was within the range of $0.115-0.143$ and $0.142-0.388 \mathrm{~L} / 100 \mathrm{~km} \times 100 \mathrm{~kg}$ for mass reduction only and powertrain adaptation purposes. Del Pero et al., (2017) performed a life-cycle assessment of 2015 European market vehicle case studies to formulate a new method to estimate fuel consumption reduction by means of FRV. The authors (ibid) concluded that the method should be extended to the mass induced energy consumption modelling to electric and hybrid vehicles. Koulton et al., (2016) performed a sensitivity analysis of a convertor housing using magnesium in the die-casting, trimming and finishing processes; their study (ibid) demonstrated that a reduction in total greenhouse gas emissions could be readily achieved. Kiani et al. (2014) conducted a structural optimization on the 1996 Dodge Neon car model, to develop a lightweight car design. The authors (ibid) replaced 22 steel parts with magnesium AZ31 and the design optimization resulted in saving $46.7 \mathrm{~kg}$ of overall weight and an approximate mass reduction of $44.3 \%$ when compared to the initial steel design.

Other applications include the usage of composite materials such as kenaf/glass fibre and glass mat thermoplastic - these materials introduce a massive challenge to designers and 
automotive engineering in optimisation of passenger vehicle design due to a large count of design variables (e.g. vehicle weight and driving conditions). An FEA investigation was carried out by Hosseinzadeh et al., (2005) on the bumper beam system manufactured from glass thermoplastic to consider the low-velocity impact performance. Davoodi et al., (2010) conducted their FEA investigation on the selection of the best geometric parameters to improve the performance of the car bumper system manufactured from kenaf/glass fibre and illustrated that vehicle performance improved via overall weight reduction. Bellingardi et al., (2013) employed major design parameters such as peak load and energy absorption to develop an optimisation evaluation criteria of an open integrated crash box and bumper beam system - thus improving crashworthiness. Yet, despite this extensive research conducted, ample opportunities remain to conduct additional studies into vehicle light-weighting and its impact upon car performance, environmental impact and safety design.

\section{METHODOLOGICAL EVALUATION OF STRESSES}

In this case study, finite element analysis (FEA) is performed to examine the Wikispeed chassis for light-weighting opportunities in three key aspects of the vehicle's design, namely: i) for body bending the rockers (or longitudinal tubes); ii) for body torsion (again the rockers but also the chassis as a whole); and iii) for crash safety - on the front crash structure (through the presentation of analytical calculations). The methodological framework adopted in this paper is defined and delineated in Figure 2 and consisted of into two phases. In phase one, a 3D CAD geometry is generated and this is followed by FEA in phase two. The combination of analysis results was used to develop the virtual model using FEA tools and the model was updated based on the correlation process.

\section{<Insert Figure 2 about here>}

Specifically, Malen's approach to conducting FE calculations for the vehicle's components is outlined for the calculations (c.f. Malen, 2011). For the body in bending analysis, a single lower longitudinal chassis beam, referred as the side rocker beam has been considered; where $\sigma_{\mathrm{CR}}$ and $\mathrm{M}_{\mathrm{CR}}$ denote the critical stress and critical bending moment respectively. The bending stiffness of the entire chassis is calculated using body bending stiffness; where $\mathrm{k}$ is a function of the total length of the beam; $L$ is the length between the supports; 1 is the rigidly fixed masses on the chassis $\mathrm{M}$; and the desired bending frequency $\left(f_{n}\right)$ can be calculated using following equations: 


$$
\begin{gathered}
\sigma_{C R}=\frac{k \pi^{2} E}{12\left(1-\mu^{2}\right)\left(\frac{b}{t}\right)^{2}} \\
\sigma_{C R}=\frac{M_{C R} y}{I} \\
k=0.09566\left(\frac{l}{L}\right)^{3} M\left(2 \pi f_{n}\right)^{2}
\end{gathered}
$$

Eq. 1

Eq. 2

Eq. 3

For the body torsion analysis, first the side rocker beam was analysed. The angle of rotation $(\theta)$ and the shear stress in each of the walls of the beam $(\tau)$ resulting from a torsional force of $500 \mathrm{Nm}$ were calculated. Secondly, the torsional stiffness of the chassis structure $(K)$ has been calculated by simplifying the chassis structure into a box of open sides. Finally, the strain in the joint (eJOI) was calculated together with the strain in each of the beams in question $(e B E A M)$. The effective torsional constant (Jeff) was calculated solely to enable the angle of rotation $(\theta)$.

$$
\begin{gathered}
J_{\text {eff }}=\frac{4 A^{2} t}{S} \\
\varnothing=\frac{T L}{G J_{e f f}} \\
\tau=\frac{T}{2 A t}
\end{gathered}
$$

Eq. 6

Initially the effective shear rigidity $((G t))$ and torsional stiffness of each side of the box $(K \mathrm{~s})$ were calculated. This allows the torsional stiffness of the entire structure to be calculated.

$$
\begin{aligned}
& (G t)_{e f f}=\frac{F b}{\delta a} \\
& K_{s}=\frac{4 k_{j}}{L^{2}} \\
& K=4 h^{2} w^{2}\left\{\frac{1}{\frac{1}{K_{\text {Front }}}+\frac{1}{K_{\text {Rear }}}+\frac{1}{K_{\text {L.Side }}}+\frac{1}{K_{\text {R.Side }}}+\frac{1}{K_{\text {Bottom }}}+\frac{1}{K_{\text {Top }}}}\right\}
\end{aligned}
$$


Joint efficiency, beam strain and joint strain for the hinge pillar and rocker pillar were used to calculate joint efficiency; the strain in the two beams and the strain in the joint respectively were calculated using the following equations:

$$
\begin{gathered}
e_{\text {beam }}=\frac{L}{6 E I}\left(3 M^{2}\right) \\
e_{\text {joint }}=\frac{M^{2}}{2 k_{j}}
\end{gathered}
$$

For crash safety calculations undertaken, the axial compressive load sought to find which side rocker beam would buckle $\left(P_{U}\right)$. For the second stage of crashworthiness calculations, the crush efficiency $(\eta)$ has been calculated ensuring the result satisfies results from the Wikispeed crash test in order to find the maximum deceleration of the cabin $\left(a_{\max }\right)$. From which, using vehicle and material data, the maximum force $\left(F_{\max }\right)$ the average force $\left(F_{\text {avg }}\right)$ and the average crush force per side rocker beam were calculated.

$$
\begin{gathered}
w_{1}=0.894 b \sqrt{\frac{\sigma_{C R}}{\sigma_{s}}} \\
w_{2}=b \sqrt{\frac{\sigma_{C R}}{\sigma_{s}}}\left(1-0.22 \sqrt{\frac{\sigma_{C R}}{\sigma_{s}}}\right) \\
P_{U}=\sigma_{s}(4 w t) \\
\eta=\frac{V_{o}^{2}}{2 \Delta a_{\max }} \\
F_{\max }=\operatorname{ma} a_{\max } \\
F_{\text {avg }}=386 t^{1.86} b^{0.14} \sigma_{s}^{0.57}
\end{gathered}
$$

\section{FINITE ELEMENT ANALYSIS OF THE WIKISPEED CAR}

The analysis of body in bending, torsion and crash worthiness enabled potential lightweighting opportunities to be explored. To allow a comparative evaluation of material performance to be completed, calculations for three different materials; structural steel BS EN 10025-3:2004, aluminium alloy 6061-T651 and magnesium EN-MB10020 were completed (refer to Table 1 for material properties; such indicates a weight saving for 
Aluminium of $0.65 \%$, and for Magnesium of 0.78\%) (Brockenbrough and Merritt, 1999; Mondolfo, 2013; Mordike and Ebert, 2001).

$<$ Table 1 about here>

\section{Body in Bending}

FEA was carried out on one of the four identical rocker beams going through the car and revealed that the maximum bending moment that aluminium rockers can endure is $8.27 \mathrm{kNm}$ per rocker before they fail. Figure 3 is a representation of the rocker made from steel with an applied moment of $23.66 \mathrm{kNm}$ to one end. The stress on the top side of the rocker is around $627 \mathrm{MPa}$ much like the critical stress found from the calculations which was 626MPa. The same calculations illustrated that by using steel, the strength of the beam will increase by $286 \%$ and would be around $33.5 \%$ cheaper; albeit a $289 \%$ increase in weight is needed. The total bending moment diagram of the rocker beam is shown in Figure 4.

$<$ Insert Figures 3 and 4 about here>

From the structural analysis of one of the four identical rocker beams, it was found that for aluminium rockers, the maximum bending moment they can endure is $8.27 \mathrm{kNm}$ per rocker before it fails. The same calculations for steel revealed that this material will increase the strength of the beam (refer to Table 2). Magnesium (as a viable alternative choice of material) is the lightest of the three materials at only $64.1 \%$ of the weight of aluminium and $22.2 \%$ of steel. The reduced weight comes at a design-cost because it is $37.4 \%$ weaker than aluminium and $78.1 \%$ weaker than steel; although the purchase price is roughly the same as aluminium. Figure 5 illustrates that the same beam made from magnesium could sustain a bending moment of $964 \mathrm{Nm}$, or a mass of approximately $490 \mathrm{~kg}$ at its centre. This gives a more reasonable factor of safety of 0.314 , thus making magnesium a suitable material for selection for the side rocker beam while considering design for bending (refer to Figure 6).

<Insert Table 2 and Figures 5 and 6 about here>

\section{Body in Torsion}

For analysis of the Wikispeed car in torsion, the calculations performed are based entirely from the CAD data available at the time of this study, which excluded dimensions of the floor 
panel. Therefore, in the simplification of the chassis structure and for the approximation of its torsional stiffness, the chassis has been considered to be a cuboid, made of tubes and with open sides. Table 3 reveals that for the torsion calculations, the magnesium beam has the worst torsional performance properties of the three materials tested under these conditions.

\section{<Insert Table 3 about here>}

Magnesium having a resultant angle of rotation almost five times that of steel which has the smallest resultant angle of rotation. This initial finding suggests that from a design for torsion stance, steel is the most suitable material - whilst such is true (and steel is by far the cheapest material), it also has the highest density. This weight implication would negatively impact fuel economy. Figure 7 illustrates the total deformation on the side frame.

\section{<Insert Figure 7 about here>}

The second set of calculations show the torsional stiffness of the entire vehicle to be 3,660 $\mathrm{Nm} / \mathrm{deg}$. This is a conservative estimate as the assumptions made in these calculations are not strictly true of the actual design. For example, the torsional stiffness added to the vehicle by the body shell, floor panel and bulkhead have not been considered as they were out of scope in this research. The value calculated therefore, solely relates to the torsional stiffness of the tubular chassis structure (See Figure 8).

\section{$<$ Insert Figure 8 about here>}

Interestingly, the strain energy in the joint is constant irrespective of material selection. It does constrain the joining method hence, a combination of adhesive bonding and mechanical fastening is suitable for lightweight automotive space frame chassis (Mohamad et al., 2017; Soo et al., 2017).

\section{CRASH SAFETY}

Although the vehicle's crashworthiness is a major design consideration, occupant safety was not the primary objective for the originally designed Wikispeed Car (Socha et al., 2013). As an established manufacturing group, the car has already complied with the minimum requirements of standardised crash testing - in this case the US-NCAP (Denning, 2012). To 
exceed this minimum test would require expensive and thorough testing (to a five-star rating) - i.e. " $\$ 10,000$ per crash plus the $\$ 14,500$ material cost of the car, and $\$ 2,500$ to deliver the car to the crash testing facility" (Kupp et al., 2015). Therefore, in order to achieve the fivestar crash rating equivalency for the lightest possible chassis, only aluminium crashworthiness was experimentally conducted. In this section, four identical rockers used in the Wikispeed car have been evaluated (through theoretical calculations) for the load they can withstand before they yield in a crash (refer to Figure 9).

$<$ Insert Figure 9 about here>

In the first stage of calculations, it can be seen that the force required to buckle the side rocker beam differs greatly with respect to material. From the second stage of calculations, it can be seen that the crush efficiency is independent of material type (refer to Table 4).

$<$ Insert Table 4 about here>

The results imply that the current beam design made from magnesium would perform worst during a crash as the force required to buckle the beam is the lowest (between $95.2 \mathrm{kN}$ and $134 \mathrm{kN}$ ). Steel has the largest bandwidth of force required for buckling and also requires the largest force for buckling (between $317 \mathrm{kN}$ and $540 \mathrm{kN}$ ). Aluminium sits between the two with a compressive force between $234 \mathrm{kN}$ and $293 \mathrm{kN}$ required to buckle the beam. For a 35 mph frontal barrier test the crash efficiency of the side rocker beam is $98.2 \%$. This means that at $35 \mathrm{mph}$, there would be no intrusion into the passenger compartment. This agrees with the findings of the Wikispeed crash test however, this calculation also implies a cabin deceleration of $28 \mathrm{~m} / \mathrm{s}^{2}$ takes place which if reduced, would also reduce the likelihood of injury. As none of the beams are expected to buckle in the said crash scenario (and therefore neither is there any intrusion into the passenger compartment), it could be argued that any of the three materials would be a valid choice for crashworthiness. However, to establish each materials' performance in more detail, further analytical calculations and numerical simulations at different speeds, alongside calculations and simulations of different crash conditions (such as a side barrier crash) should be carried out. Further investigation should be conducted on the frontal crash structure to evaluate the static and dynamic stiffness, and 
change in the structural response using the magnesium and steel material models available in LS-DYNA.

\section{DISCUSSION OF THE WIKISPEED CAR}

As the rockers have been made from a square tube with relatively thick walls - the consequence is that the $\mathrm{b} / \mathrm{t}$ ratio is 33.9 meaning that the beam will fail in yielding and not buckling. The desired structural resonance frequency should be in the region of 22-25 Hz. Calculations have been made to determine the body stiffness to reach a structural resonance frequency of $25 \mathrm{~Hz}$. For the side rocker beam, it can be seen that with its current material selection, the beam would buckle under a bending moment of $1560 \mathrm{Nm}$ or more. This equates to a mass of approximately $780 \mathrm{~kg}$ being placed at the centre of the beam, which is more than the total mass of the vehicle and more than twice that of the rigidly fixed masses.

The bending moment imparted on the beam due to the rigidly fixed masses (as well as the passengers) is unlikely to exceed $964 \mathrm{Nm}$ and as there are two side rocker beams sharing this load, thus resulting in a minimum safety factor of two. This material change for the two beams would also result in a weight saving of $8 \mathrm{~kg}$, while costing approximately $£ 12$ less, based on the material mean cost per unit mass. Therefore, evaluating the results from the bending stiffness of the car chassis, it is highly recommended to change the material from aluminium to magnesium to correlate the theoretical results with the mechanical analysis. Magnesium will also save $3 \mathrm{~kg}$ weight per beam which is $12 \mathrm{~kg}$ on the whole chassis for the same material price per beam. The results also indicate that the bending stiffness is independent of material type and therefore, material selection will not impact upon this characteristic of the chassis' mechanical performance. One major issue is the choice of profile for the rockers. With the $\mathrm{b} / \mathrm{t}$ ratio of 34 , the rockers are going to fail by yielding and not by buckling.

As high fuel economy is a key design criterion for the vehicle, the degree to which torsional performance compromise can be made in favour of reducing weight, should be the main consideration. To this end, magnesium or aluminium both represent viable alternatives - the decision depends upon whether a weight saving of $36 \%$ justifies having a beam with half the torsional performance (that is $3.29^{\circ}$ for aluminium vs $6.67^{\circ}$ for magnesium?). Accounting for the parts left out in the assumptions would most likely account for this deficiency but should 
be further investigated in order to make a valid assertion. From the third and final set of body in torsion calculations, it can be seen that magnesium has the highest joint efficiency $(77.1 \%)$, steel has the smallest $(41.8 \%)$ and aluminium sits between the two with $(68.4 \%)$. The strain energy in the rocker beam is ten times that of the B-pillar due to their respective lengths, thus there would be a larger improvement of vehicle torsional performance by improving the torsional performance of the side rocker beam. Rocker beams made of magnesium show the greatest strain energy, namely: $5.62 \times 10^{-7}$. As strain energy is equal to change in length divided by original length, it is expected that magnesium would show the largest deformation. This is reflected in the initial calculations, showing magnesium to have the greatest angle of rotation. Clearly this is not favourable, especially for a vehicle which already has a potentially relatively low torsional stiffness. To compensate for the material's (and potentially vehicle's) torsional deficiency, design work could be undertaken to add extra beams in the form of braces or a lattice structure to improve torsional stiffness, while still reducing the overall mass of the vehicle.

Fibre reinforced composite structures, such as the Wikispeed body shell, have exhibited energy absorption greater than similar metal structures (Lu et al., 2018). Hence, it is necessary that for a full understanding of the vehicle's crashworthiness, this structure should be included in future crash analysis. The forces $F_{\max }$ and $F_{\text {avg }}$ calculated in the second stage of calculations relate to the entire vehicle. In order to find the load in each of the side rocker beams the load must be partitioned. Figure 9 reveals that there are two main beams running along the length of each side of the vehicle (the lower being the side rocker beam) and each are identical in both size and shape. $C F_{\text {avg }}$ is the average force per each of these beams, showing a force of $133 \mathrm{kN}$ exerted on the aluminium beam, $129 \mathrm{kN}$ on the steel beam and $70.4 \mathrm{kN}$ on the magnesium beam. Comparing these values to those required to buckle the beams (by dividing the lowest force needed for buckling by the maximum force in the beam during the crash), reveals a worst-case safety factor of around 1.76 for aluminium, 2.46 for steel and 1.35 for magnesium, thus implying steel is also the most suitable material for the crashworthiness of the vehicle. When evaluating the crush efficiency, the eligible crush distance was taken as from the front bumper to the fire-wall or where the rockers begin. The analysis showed a crush efficiency of $98.16 \%$, which means that for the car to be able to stop within the eligible crush distance it cannot do it without exceeding a maximum deceleration of $28 \mathrm{~m} / \mathrm{s}^{2}$. With a maximum force of $193 \mathrm{kN}$ (calculated with max deceleration of $28 \mathrm{~m} / \mathrm{s}^{2}$ ) the rockers have a large margin before they would yield. 
The primary factors that affect the fuel economy are regular travelling, weather, vehicle age and most importantly, traffic related factors. It can be estimated that if the Wikispeed Car (or any ICE engine vehicle) travels on the newly developed eco-system roads using advanced navigation systems, that there would be a saving of between $8.73 \%$ to $42.15 \%$ depending upon travel conditions i.e., traffic on the road (Zhou et al., 2016). The water pump and the air-conditioner of the passenger vehicle are mostly affected due to the ambient temperature, whilst wind effects can also contribute in reducing the fuel economy by approximately up to 1\% (U.S. Department of Energy, 2018). The engine is the most important factor that affects the fuel economy calculation due to engine loading, vehicle speed and the driver's aggressiveness, where the Wikispeed Car would have fuel economy of 5-20\% on the flat roads superior to the car been driven on the hilly roads (Ciuffo and Fontaras, 2017). Another potential factor to increase the fuel economy of the Wikispeed Car, can be obtained by using optimal traffic light to vehicle communication system which would improve the fuel economy by almost $25 \%$ through the interaction between the driver and the traffic lights (Nasir et al., 2014). Hence, although vehicle light-weighting can have a significant impact upon fuel economy, other external factors must also be considered as perhaps optimisation type problems. Optimisation of travel could be used via a coalescence of disruptive technologies that are dominating contemporary car manufacturing processes, for example, Industry 4.0 (Wand et al., 2015) to build cars with advanced wireless monitoring and management systems. These technologies are already being adopted to varying extents to remove human error and increase vehicle performance (Lee et al., 2015) - this trend is most likely set to continue.

\section{CONCLUSION}

Due to tougher EU legislations being introduced on reducing $\mathrm{CO}_{2}$ emissions, automotive manufacturers are increasingly applying lightweight as a technological solution to obtain desirable environmental impact improvements. Vehicle mass reduction can be obtained through downsizing but also through substitution of the traditional automotive materials by lightweight materials, such as magnesium. Although aluminium alloy application has gained prominence, magnesium proves to be a promising contender to meet future demands of passenger vehicles. The research findings presented suggest that for the Wikispeed Car, magnesium is the right material choice. With the key design criteria of the Wikispeed being high fuel economy, the potential benefits highlighted in this paper from substituting aluminium alloy 6061-T651 for magnesium EN-MB10020 are noteworthy. The ability to 
improve the fuel economy by $10 \%$ and reduce the production cost at the same time is useful information for any automotive designer - especially those in the open-source crowd-funded domain. Nevertheless, with the b/t ratio of 34 , the rockers are going to fail by yielding and not by buckling. As mentioned the crush length of frontal impact structure is $27 \%$ short. The way the crash beams have been orientated they are not going to buckle or yield - they are simply going to collapse. However, the cross bar needs to be orientated in this way to distribute the load between both sides, and the thickness of the beams might give it the needed rigidity to act as a good crash structure. It is therefore advisable for engineering designers to consider changing the material of the chassis to magnesium EN-MB10020 while implementing braces; although this will add more material to the vehicle it will be compensated for in the large reduction in vehicle mass of $110 \mathrm{~kg}$. In addition to this research presented, a wider and more holistic view of passenger vehicle usage is required, beyond the design of the car itself. Such work should involve an integrated coalescence of disruptive innovative technologies such as global positioning systems, computational intelligence, internet of things and sensor based technologies (perhaps under the guise of Industry 4.0) to optimise passenger travel. 


\section{REFERENCES}

Alsabbagh, M., Siu, Y.L., Guehnemann, A. and Barrett, J. (2017) Mitigation of $\mathrm{CO}_{2}$ Emissions from the Road Passenger Transport Sector in Bahrain, Mitigation And Adaptation Strategies For Global Change, 22(1), pp. 99-119. DOI: Https://Doi.Org/10.1007/S11027-015-9666-8

Attaran, M. (2017) The Rise of 3-D Printing: The Advantages of Additive Manufacturing Over Traditional Manufacturing, Business Horizons, 60(5), pp. 677-688. DOI: Https://Doi.Org/10.1016/J.Bushor.2017.05.011

Barton, D. and Fieldhouse, J. (2018) Vehicle Structures and Materials, Automotive Chassis Engineering. pp. 215-254. DOI: Https://Doi.Org/10.1007/978-3-319-72437-9_4

Belingardi, G., Beyene, T. and Koricho, E. (2013) Geometrical Optimization of Bumper Beam Profile Made of Pultruded Composite by Numerical Simulation, Composite Structures, 102, pp. 217-225. DOI: Https://Doi.Org/10.1016/J.Compstruct.2013.02.013

Betancur, E., Mejía-Gutiérrez, R., Osorio-Gómez, G. and Arbelaez, A. (2017) Design of Structural Parts for a Racing Solar Car, Advances on Mechanics, Design Engineering and Manufacturing, Springer, pp. 25-32. DOI: Https://Doi.Org/10.1007/978-3-31945781-9_3

Brockenbrough, R.L. and Merritt, F.S. (1999) Structural Steel Designer's Handbook, Mcgraw-Hill New York.

Cole, G.S. (2016) Summary of Magnesium Vision 2020: A North American Automotive Strategic Vision For Magnesium, Essential Readings In Magnesium Technology, pp. 35-40. DOI: Https://Doi.Org/10.1002/9781118859803.Ch5

Cole, L. (2017) The Classic Car Adventure: Driving Through History on the Road to Nostalgia, Pen and Sword.

Ciuffo, B. and Fontaras, G. (2017) Models and Scientific Tools for Regulatory Purposes: The Case of $\mathrm{CO}_{2}$ Emissions from Light Duty Vehicles in Europe, Energy Policy, 109, pp. 76-81. DOI: Https://Doi.Org/10.1016/J.Enpol.2017.06.057

Dafermos, G. (2015) Transforming the Productive Base of the Economy Through the Open Design Commons and Distributed Manufacturing, Journal of Peer Production, Vol. 7.

Danilecki, K., Mrozik, M. and Smurawski, P. (2017) Changes in the Environmental Profile of a Popular Passenger Car over the Last 30 Years-Results of a Simplified LCA Study, Journal of Cleaner Production, 141, pp. 208-218. DOI: Https://Doi.Org/10.1016/J.Jclepro.2016.09.050

Davoodi, M., Sapuan, S., Ahmad, D., Ali, A., K, A. and Jonoobi, M. (2010) Mechanical 
Properties of Hybrid Kenaf/Glass Reinforced Epoxy Composite for Passenger Car Bumper Beam, Materials \& Design. 31, pp. 4927-4932. DOI: Https://Doi.Org/10.1016/J.Matdes.2011.06.011

Delogu, M., Del Pero, F. and Pierini, M. (2016) Lightweight Design Solutions in the Automotive Field: Environmental Modelling Based on Fuel Reduction Value Applied to

Diesel Turbocharged Vehicles, $\quad$ Sustainability, 8(11). DOI: Https://Doi.Org/10.20944/Preprints201611.0059.V1

Denning, S. (2012) How Agile can Transform Manufacturing: The Case of Wikispeed, Strategy $\quad \& \quad$ Leadership, $\quad 40, \quad$ pp. $\quad 22-28 . \quad$ DOI: Https://Doi.Org/10.1108/10878571211278859

Ding, N., Gao, F., Wang, Z. and Yang, J. (2016) Life Cycle Energy and Greenhouse Gas Emissions of Automobiles Using Aluminum in China, Journal of Industrial Ecology, 20(4), pp. 818-827. DOI: Https://Doi.Org/10.1111/Jiec.12298

Dlugosch, M., Volk, M., Lukaszewicz, D., Fritsch, J. and Hiermaier, S. (2017) Suitability Assessments for Advanced Composite-Metal Hybrid Material Systems in Automotive Crash Structural Applications, International Journal of Automotive Composites, 3(1), pp. 14-28. DOI: Https://Doi.Org/10.1504/Ijautoc.2017.086513

Fechner, D., Blawert, C., Hort, N., Dieringa, H. and Kainer, K.U. (2013) Development of a Magnesium Secondary Alloy System for Mixed Magnesium Post-Consumer Scrap, Materials Science and Engineering: A, 576(No. Supplement C), pp. 222-230. DOI: Https://Doi.Org/10.1016/J.Msea.2013.03.053

Fernández, R.Á. (2018) A More Realistic Approach to Electric Vehicle Contribution to Greenhouse Gas Emissions in the City, Journal of Cleaner Production, 172, pp. 949959. DOI: Https://Doi.Org/10.1016/J.Jclepro.2017.10.158

Fridlyander, I.N., Sister, V.G., Grushko, O.E., Berstenev, V. V, Sheveleva, L.M. and Ivanova, L.A. (2002) Aluminum Alloys: Promising Materials in the Automotive Industry, Metal Science and Heat Treatment, 44(9), pp. 365-370. DOI: Https://Doi.Org/10.1023/B:Msat.0000009778.88374.41

Grey, C., and Tarascon, J. (2017) Sustainability and in Situ Monitoring in Battery Development, Nature Materials, 16, pp.45. DOI: Https://Doi.Org/10.1038/Nmat4777

Gur, Yuksel And Pan, Jian And Li, Wanlu and Wagner, D.A. (2016) Development of Vehicle Dash and Floor Subsystem Sound Packages for Lightweight Vehicle, Inter-Noise and Noise-Con Congress and Conference Proceedings, 252(2).

Harvey, L.D.D. (2018) Resource Implications of Alternative Strategies for Achieving Zero 
Greenhouse Gas Emissions from Light-Duty Vehicles by 2060, Applied Energy, Elsevier, 212, pp. 663-679. DOI: Https://Doi.Org/10.1016/J.Apenergy.2017.11.074

He, P.H.Y. (2017) Hot Stamping Advanced Manufacturing Technology of Lightweight Car Body, Springer, Singapore. DOI: Https://Doi.Org/10.1007/978-981-10-2401-6_3

Henriksson, F. and Johansen, K. (2016) An Outlook on Multi Material Body Solutions in the Automotive Industry - Possibilities and Manufacturing Challenges, SAE Technical Paper, SAE International. DOI:Https://Doi.Org/10.4271/2016-01-1332.

Holmes, K.J. (2017) A Century of Environmental Technologies for Light-Duty Vehicles, SAE International Journal of Engines, 10(2017-01-0119), pp. 160-172. DOI: Https://Doi.Org/10.4271/2017-01-0119

Homchaudhuri, B., Vahidi, A. and Pisu, P. (2017) Fast Model Predictive Control-Based Fuel Efficient Control Strategy for a Group of Connected Vehicles in Urban Road Conditions, IEEE Transactions On Control Systems Technology, 25, pp.760-767. DOI: Https://Doi.Org/10.1109/Tcst.2016.2572603

Hong, K. and Shin, Y. (2017) Prospects of Laser Welding Technology in the Automotive Industry: A Review. Journal of Materials Processing Technology, 245, pp.46-69. DOI: Https://Doi.Org/10.1016/J.Jmatprotec.2017.02.008

Hosseinzadeh, R., Shokrieh, M. and Lessard, L. (2005) Parametric Study of Automotive Composite Bumper Beams Subjected to Low-Velocity Impacts, Composite Structures, 68, pp. 419-427. DOI: Https://Doi.Org/10.1016/J.Compstruct.2004.04.008

Hourmand, M., Farahany, S., Sarhan, A.A.D. and Noordin, M.Y. (2015) Investigating the Electrical Discharge Machining (EDM) Parameter Effects on Al-Mg2Si Metal Matrix Composite (MMC) for High Material Removal Rate (MRR) and Less EWR--RSM Approach, The International Journal of Advanced Manufacturing Technology, 77(5-8), pp. 831-838. DOI: Https://Doi.Org/10.1007/S00170-014-6491-2

Isenstadt, A., German, J., Bubna, P., Wiseman, M., Venkatakrishnan, U., Abbasov, L. and Guillen, P. (2016) Lightweighting Technology Development and Trends in US Passenger Vehicles, International Council on Clean Transportation, Washington, DC.

Jinturkar, A., Channa, R., Mistry, R. and Deshmukh, B. (2017) Weight Reduction of FSAE Vehicle Using TRIZ Principle, International Conference on Research into Design, pp. 861-870. DOI: Https://Doi.Org/10.1007/978-981-10-3518-0_74

Joost, W. and Krajewski, P. (2017) Towards Magnesium Alloys for High-Volume Automotive Applications, Scripta Materialia, 128, pp. 107-112. DOI: Https://Doi.Org/10.1016/J.Scriptamat.2016.07.035 
Joost, W.J. and Krajewski, P.E. (2017) Towards Magnesium Alloys for High-Volume Automotive Applications, Scripta Materialia, 128(Supplement C), pp. 107-112. DOI: Https://Doi.Org/10.1016/J.Scriptamat.2016.07.035

Jostins, J. and Kendall, K. (2017) Interfaces, Cracks and Toughness: City Cars Made from Composites, In Beaumont, P.W.R., Soutis, C. and Hodzic, A. (Eds.) The Structural Integrity of Carbon Fiber Composites: Fifty Years of Progress and Achievement of the Science, Development and Applications, Springer International Publishing, Cham, pp. 645-663. DOI: Https://Doi.Org/10.1007/978-3-319-46120-5_22

Kiani, M., Gandikota, I., Rais-Rohani, M. and Motoyama, K. (2014) Design of Lightweight Magnesium Car Body Structure Under Crash and Vibration Constraints, Journal of Magnesium alloys, 2(2), pp. 99-108. DOI: Https://Doi.Org/10.1016/J.Jma.2014.05.005

Klassen, M., Skupin, J., Schubert, E. and Sepold, G. (1998) Development of Seam Imperfections Due to Process Immanent Resonances by Laser Beam Welding of Aluminium Alloys, Proceedings of the Conference on EKLAT'98, Hanover, Germany, September 22-23, pp. 297-302.

Koltun, P., Tharumarajah, A. and Ramakrishnan, S. (2016) Life Cycle Environmental Impact of Magnesium Automotive Components, In Mathaudhu, S.N., Luo, A.A., Neelameggham, N.R., Nyberg, E.A. and Sillekens, W.H. (Eds.), Essential Readings In Magnesium Technology, Springer International Publishing, Cham, pp. 175-180. DOI: Https://Doi.Org/10.1002/9781118859803.Ch29

Kostakis, V., Niaros, V., Dafermos, G. and Bauwens, M. (2015) Design Global, Manufacture Local: Exploring the Contours of an Emerging Productive Model, Futures, Elsevier, 73, pp. 126-135. DOI: Https://Doi.Org/10.1016/J.Futures.2015.09.001

Lee, J., Hung, A-K. and Yang, S. (2015) Service Innovation and Smart Analytics for Industry 4.0 and Big Data Environment, Procedia CIRP, Vol. 16, pp 3-8. DOI: https://doi.org/10.1016/j.procir.2014.02.001

Li, Y., Lin, Z., Jiang, A. And Chen, G. (2003) Use of High Strength Steel Sheet for Lightweight and Crashworthy Car Body, Materials \& Design, 24(3), pp. 177-182. DOI: Https://Doi.Org/10.1016/S0261-3069(03)00021-9

Lu, R., Gao, W., Hu, X., Liu, W., Li, Y. and Liu, X. (2018) Crushing Analysis and Crashworthiness Optimization of Tailor Rolled Tubes with Variation of Thickness and Material Properties, International Journal Of Mechanical Sciences, 136, pp. 67-84. DOI: Https://Doi.Org/10.1016/J.Ijmecsci.2017.12.020 
Luján, J.M., Bermúdez, V., Dolz, V. and Monsalve-Serrano, J. (2018) An Assessment of the Real-World Driving Gaseous Emissions from a Euro 6 Light-Duty Diesel Vehicle Using a Portable Emissions Measurement System (PEMS), Atmospheric Environment, 174, pp. 112-121. DOI: Https://Doi.Org/10.1016/J.Atmosenv.2017.11.056

Luk, J.M., Kim, H.C., De Kleine, R., Wallington, T.J. and Maclean, H.L. (2017) Review of the Fuel Saving, Life Cycle GHG Emission, and Ownership Cost Impacts of Lightweighting Vehicles With Different Powertrains, Environmental Science \& Technology, 51(15), pp. 8215-8228. DOI: Https://Doi.Org/10.1021/Acs.Est.7b00909

Luo, A.A., Nyberg, E.A., Sadayappan, K. and Shi, W. (2016) Magnesium Front End Research and Development: A Canada-China-USA Collaboration. In Essential Readings in Magnesium Technology. pp. 41-48. Springer, Cham. DOI: Https://Doi.Org/10.1007/978-3-319-48099-2_6

Macwan, A. and Chen, D.L. (2016) Ultrasonic Spot Welding of Rare-Earth Containing ZEK100 Magnesium Alloy to 5754 Aluminum Alloy, Materials Science and Engineering: $\quad A, \quad$ 666(Supplement $\quad$ C), pp. 139-148. DOI: Https://Doi.Org/10.1002/9781119274803.Ch23

Malen, D.E. (2011) Fundamentals of Automobile Body Structure Design. DOI: Https://Doi.Org/10.4271/R-394

Melado, A., Nishikawa, A., Goldenstein, H., Giles, M. and Reed, P.A. (2017) Effect of Microstructure on Fatigue Behaviour of Advanced High Strength Ductile Cast Iron Produced by Quenching and Partitioning Process, International Journal of Fatigue, 104, pp.397-407. DOI: Https://Doi.Org/10.1016/J.Ijfatigue.2017.07.009

Mohamad, M.L., Rahman, M.T.A., Khan, S.F., Basha, M.H., Adom, A.H. and Hashim, M.S.M. (2017) Design and Static Structural Analysis of a Race Car Chassis for Formula Society of Automotive Engineers (FSAE) Event, Journal of Physics: Conference Series, 908, p. 12042. DOI: Https://Doi.Org/10.1088/1742-6596/908/1/012042

Mohrbacher, H. (2013). Reverse Metallurgical Engineering Towards Sustainable Manufacturing of Vehicles Using $\mathrm{Nb}$ and Mo Alloyed High Performance Steels, Advanced Manufacturing, 1, pp. 28 - 41. DOI: Http://Dx.Doi.Org/10.1007/S40436-0130002-9.

Mondolfo, L.F. (2013) Aluminum Alloys: Structure and Properties, Butterworths, London Mordike, B.L. and Ebert, T. (2001) Magnesium: Properties-Applications-Potential, Materials Science and Engineering: A, 302(1), pp. 37-45. DOI: Https://Doi.Org/10.1016/S0921-5093(00)01351-4 
Muthuraj, R., Thiyagarajan, S., Vignesh, E., Kannan, C. and Praphu, D. (2017) The Disc Gutter Wheel for Commercial Vehicles, a Solution Ffr Overheating Problems with Robustness in Design. DOI: Https://Doi.Org/10.4271/2017-26-0369

Nasir, M. K., Md Noor, R., Kalam, M. A. and Masum, B. M. (2014) Reduction of Fuel Consumption and Exhaust Pollutant Using Intelligent Transport Systems, The Scientific World Journal. Http://Doi.Org/10.1155/2014/836375

Nikowitz, M. (2016) Advanced Hybrid and Electric Vehicles: System Optimization and Vehicle Integration, Springer, London.

Niu, X.P., Skszek, T., Fabischek, M. and Zak, A. (2014) Low Temperature Warm Forming Of Magnesium ZEK 100 Sheets for Automotive Applications, Materials Science Forum, 783, pp. 431-436. DOI: Https://Doi.Org/10.4028/Www.Scientific.Net/Msf.783-786.431

Onar, O.C., Campbell, S.L., Seiber, L.E., White, C.P., Chinthavali, M.S., Tang, L. and Chambon, P.H. (2016) Oak Ridge National Laboratory Wireless Charging of Electric Vehicles-CRADA Report. DOI: Https://Doi.Org/10.2172/1263875

Pero, F. Del, Delogu, M. and Pierini, M. (2017) The Effect of Lightweighting in Automotive LCA Perspective: Estimation of Mass-Induced Fuel Consumption Reduction for Gasoline Turbocharged Vehicles, Journal of Cleaner Production, 154(Supplement C), pp. 566-577. DOI: Https://Doi.Org/10.1016/J.Jclepro.2017.04.013

Pinamonti, S.A., Brancale, D., Meister, G. and Mendoza, P. (2017) A Correlation Methodology Between AVL Mean Value Engine Model and Measurements with Concept Analysis of Mean Value Representation for Engine Transient Tests, SAE Technical Paper, SAE International. DOI: Https://Doi.Org/10.4271/2017-24-0053

Pradeep, S.A., Iyer, R.K., Kazan, H. and Pilla, S. (2017) Automotive Applications of Plastics: Past, Present, and Future. In Applied Plastics Engineering Handbook (Second Edition). pp. 651-673. DOI: Https://Doi.Org/10.1016/B978-0-323-39040-8.00031-6

Roth, R., Clark, J. and Kelkar, A. (2001) Automobile Bodies: Can Aluminum be an Economical Alternative to Steel?, JOM, 53(8), pp. 28-32. DOI: Https://Doi.Org/10.1007/S11837-001-0131-7

Sarlioglu, B., Morris, C.T., Han, D. and Li, S. (2017) Driving Toward Accessibility: A Review of Technological Improvements for Electric Machines, Power Electronics, and Batteries for Electric and Hybrid Vehicles, IEEE Industry Applications Magazine, 23(1), pp. 14-25. DOI: Https://Doi.Org/10.1109/Mias.2016.2600739

Sasanka, C.T. and Kumar, D.S. (2017) Magnesium and its Alloys. In Lightweight and Sustainable Materials for Automotive Applications. pp. 329-368. CRC Press. DOI: 
Https://Doi.Org/10.1201/9781315152967-11

Shi, Y., Zhu, P., Shen, L. and Lin, Z. (2007) Lightweight Design of Automotive Front Side Rails with TWB Concept, Thin-Walled Structures, 45(1), pp. 8-14. DOI: Https://Doi.Org/10.1016/J.Tws.2007.01.013

Skar, J.I. and Albright, D. (2016) Emerging Trends in Corrosion Protection of Magnesium Die-Castings, Essential Readings in Magnesium Technology, pp. 585-591. DOI: Https://Doi.Org/10.1002/9781118859803.Ch93

Socha, D., Folsom, T.C. and Justice, J. (2013) Applying Agile Software Principles and Practices for Fast Automotive Development, Proceedings of the FISITA 2012 World Automotive Congress, pp. 1033-1045. DOI: Https://Doi.Org/10.1007/978-3-642-337383_8

Soo, V.K., Peeters, J., Paraskevas, D., Compston, P., Doolan, M. and Duflou, J.R. (2017) Sustainable Aluminium Recycling of End-of-Life Products: A Joining Techniques Perspective, Journal of Cleaner Production, 178, pp. 119-132. DOI: Https://Doi.Org/10.1016/J.Jclepro.2017.12.235

Sternlund, S., Strandroth, J., Rizzi, M., Lie, A. and Tingvall, C. (2017) The Effectiveness of Lane Departure Warning Systems-A Reduction in Real-World Passenger Car Injury Crashes, Traffic Injury Prevention, Taylor \& Francis, 18(2), pp. 225-229. DOI: Https://Doi.Org/10.1080/15389588.2016.1230672

Suh, N.P. and Cho, D.H. (2017) Making the Move: From Internal Combustion Engines to

Wireless Electric Vehicles, The on-Line Electric Vehicle, pp. 3-15. DOI: Https://Doi.Org/10.1007/978-3-319-51183-2_1

Tang, H. (2017) Comprehensive Considerations on Material Selection for Lightweighting Vehicle Bodies Based on Material Costs and Assembly Joining Technologies, International Journal of Manufacturing, Materials, and Mechanical Engineering (IJMMME), 7, pp.1-14. DOI: Https://Doi.Org/10.4018/Ijmmme.2017100101

Taub A., Krajewski P. and Luo A. (2007) The Evolution of Technology for Materials Processing Over the Last 50 Years: The Automotive Example, The Journal of the Minerals, Metals \& Materials Society, 59(2), pp. 48-57. DOI: Https://Doi.Org/10.1007/S11837-007-0022-7

Taub, A. and Luo, A. (2015) Advanced Lightweight Materials and Manufacturing Processes for Automotive Applications, MRS Bulletin, 40, pp. 1045-1054. DOI: Https://Doi.Org/10.1557/Mrs.2015.268

Timmers, V.R.J.H. and Achten, P.A.J. (2018) Non-Exhaust PM Emissions from Battery 
Electric Vehicles, Non-Exhaust Emissions, pp. 261-287. DOI: Https://Doi.Org/10.1016/B978-0-12-811770-5.00012-1

U.S. Department of Energy. <Https://Www.Fueleconomy.Gov/Feg/Evtech.Shtml>. Date Accessed: 17/08/2018.

Wang, L., Torngren, M. and Onori, M. (2015) Current Status and Advancement of CyberPhysical Systems in Manufacturing, Journal of Manufacturing Systems, 37(2), pp. 517527. DOI: https://doi.org/10.1016/j.jmsy.2015.04.008

Webb, J. And Wilson, C. (2017) Powering the Driverless Electric Car of the Future, Innovation and Disruption at the Grid's Edge, pp. 101-122. DOI: Https://Doi.Org/10.1016/B978-0-12-811758-3.00006-1

Xiong, F., Wang, D., Ma, Z., Chen, S., Lv, T. and Lu, F. (2018) Structure-Material Integrated Multi-Objective Lightweight Design of the Front End Structure of Automobile Body, Structural and Multidisciplinary Optimization, 57, pp. 829-847. DOI: Https://Doi.Org/10.1007/S00158-017-1778-1

Xue, Z., Elango, A. and Fang, J. (2016) Multidisciplinary Design Optimization of Vehicle Weight Reduction, SAE International Journal of Materials and Manufacturing, 9(201601-0301), pp. 393-399. DOI: Https://Doi.Org/10.4271/2016-01-0301

Zhao, M.-C., Liu, M., Song, G. and Atrens, A. (2008) Influence of the B-Phase Morphology on the Corrosion of the Mg Alloy AZ91, Corrosion Science, 50(7), pp. 1939-1953. DOI: Https://Doi.Org/10.1016/J.Corsci.2008.04.010

Zhou, M., Jin, H. and Wang, W. (2016) A Review of Vehicle Fuel Consumption Models to Evaluate Eco-Driving and Eco-Routing, Transportation Research Part D: Transport and Environment, 49, pp. 203-218. DOI: Https://Doi.Org/10.1016/J.Trd.2016.09.008 
Figure 1 - Weight Reduction Potential for High Strength Steel

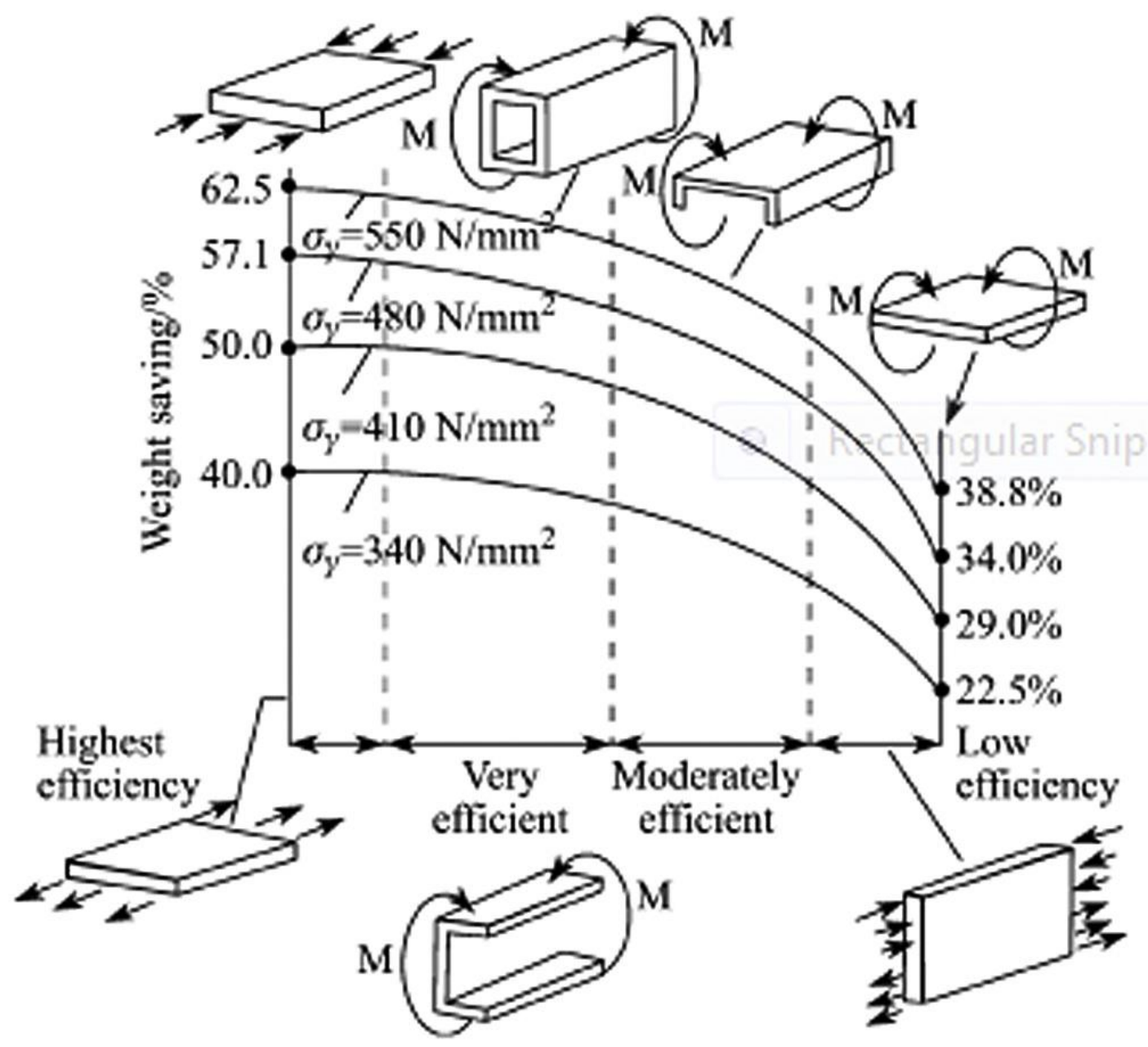


Figure 2 - The Flow Chart of the Methodology Used in this Paper

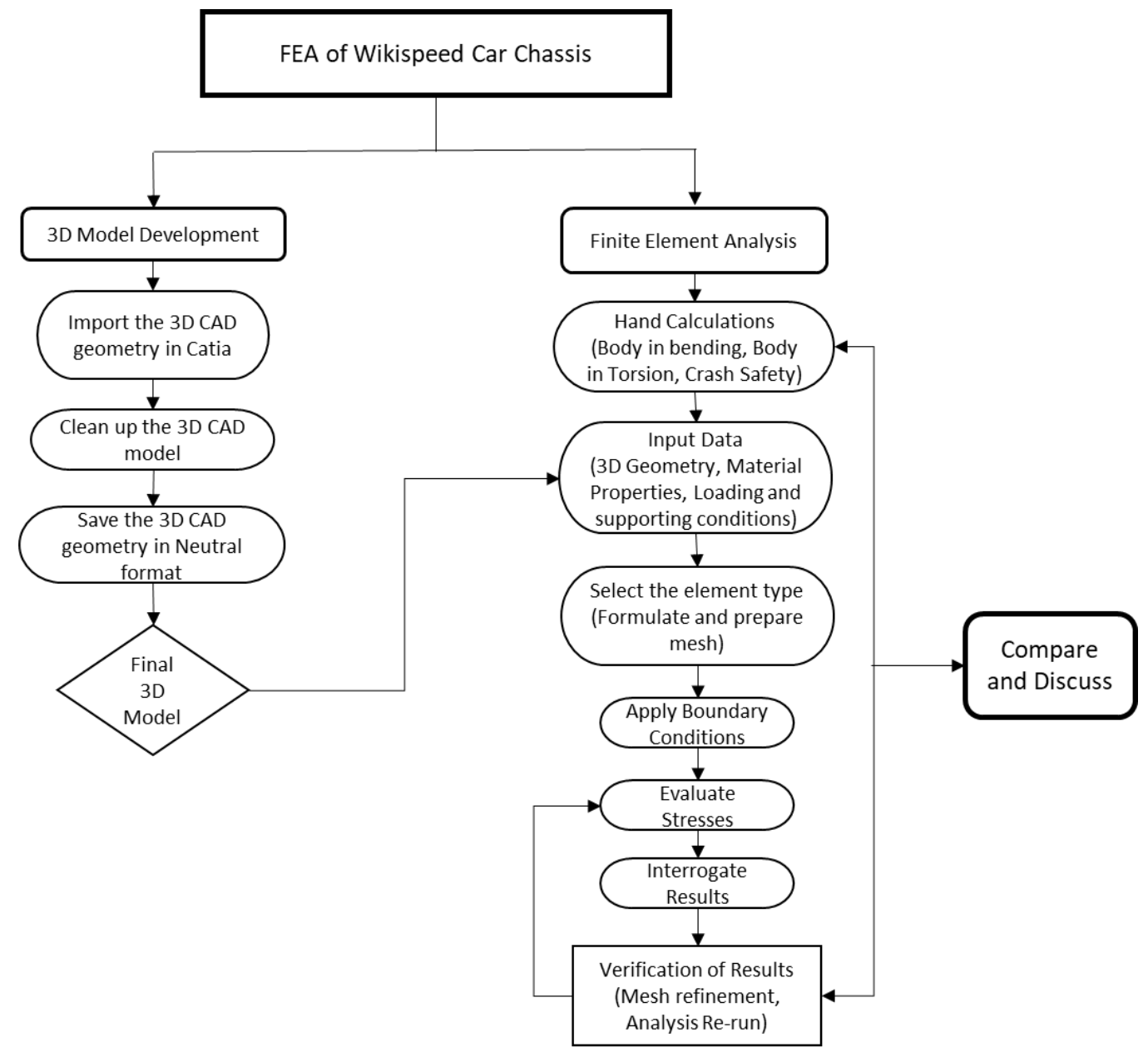


Table 1 - Material Properties

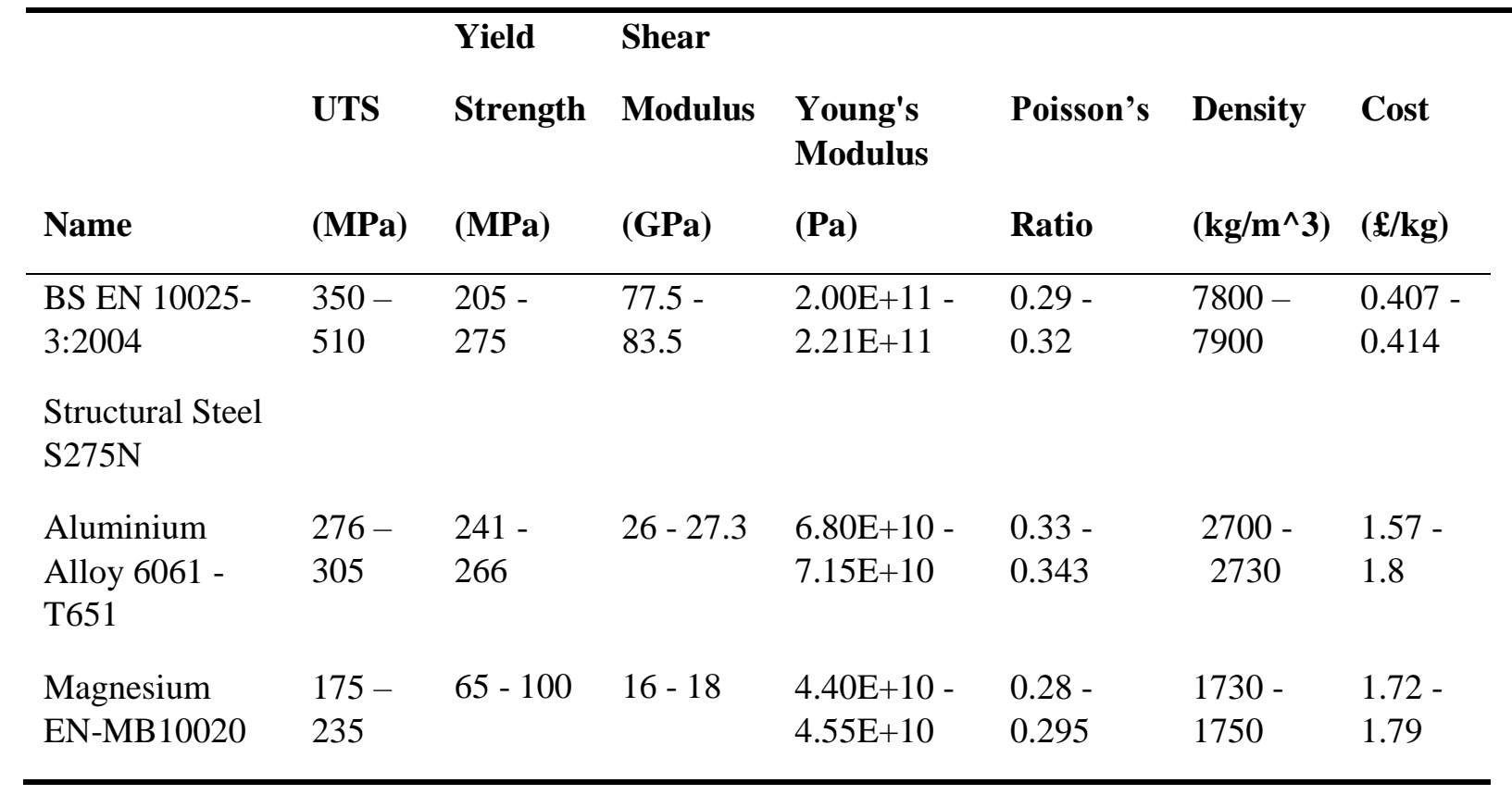


Figure 3 - FE Analysis on One of the Rocker Beams Made from Steel

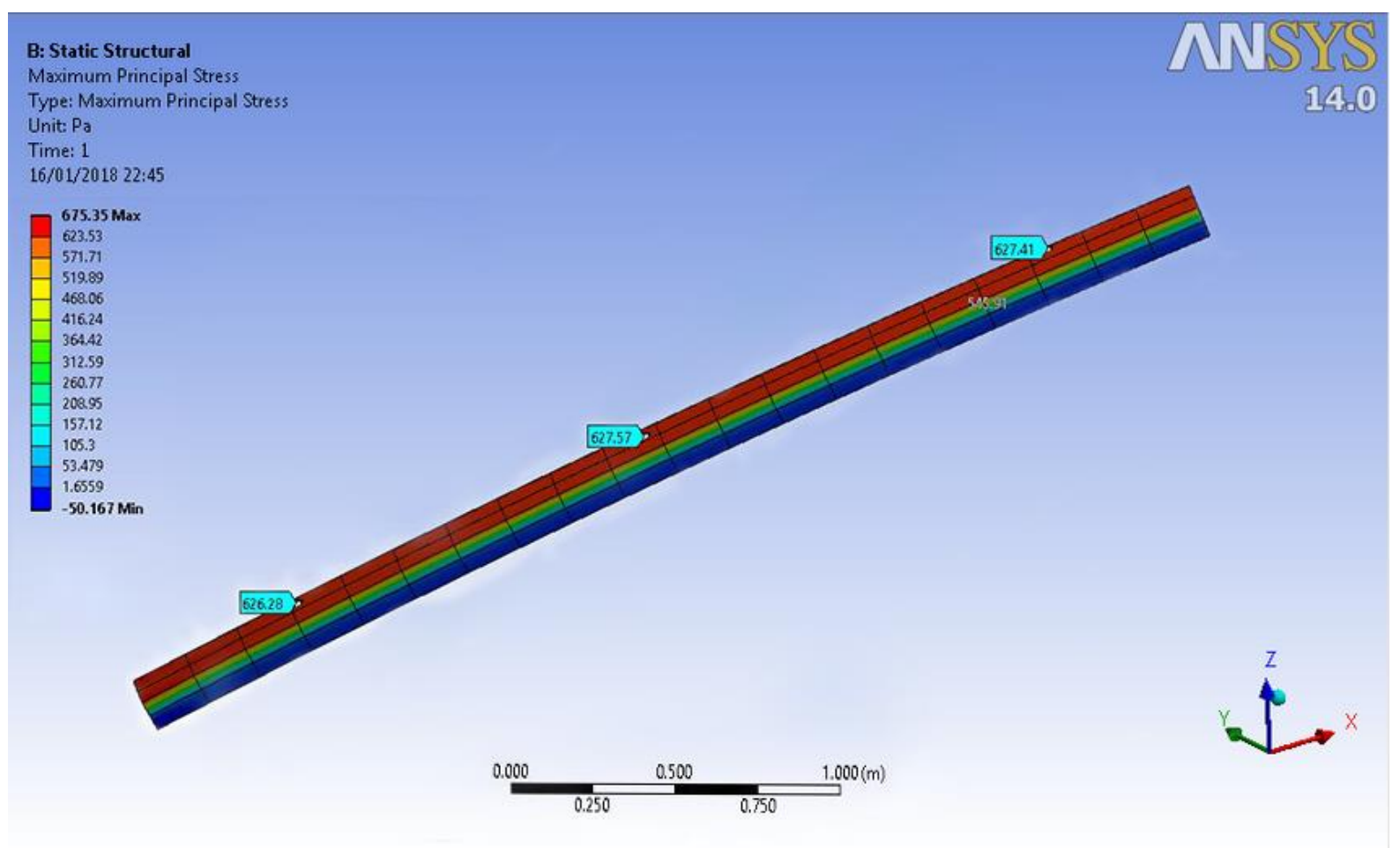


Figure 4 - Forces Acting on the Rocker Beam

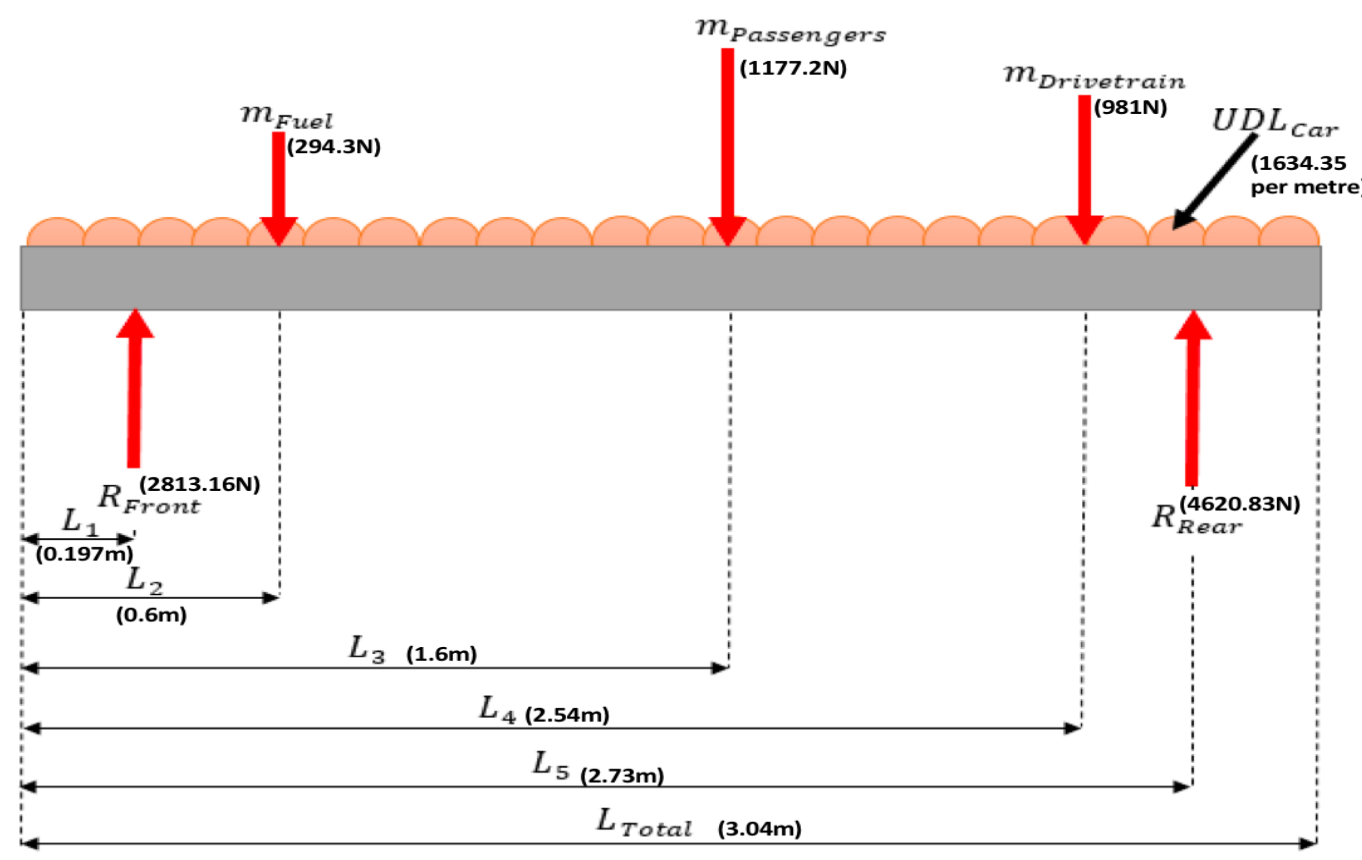


Table 2 - Results of Rocker Bending Analysis

\begin{tabular}{cccc}
\hline Material & Steel & Aluminium & Magnesium \\
\hline$\sigma_{\mathrm{CR}}$ & $626.4 \mathrm{MPa}$ & $218.9 \mathrm{MPa}$ & $136.9 \mathrm{MPa}$ \\
$\mathrm{M}_{\mathrm{CR}}$ & $23.66 \mathrm{kNm}$ & $8.27 \mathrm{kNm}$ & $5.17 \mathrm{kNm}$ \\
Weight & $31.6 \mathrm{~kg}$ & $10.92 \mathrm{~kg}$ & $7 \mathrm{~kg}$ \\
Price & $£ 13.08$ & $£ 19.66$ & $£ 19.55$ \\
\hline
\end{tabular}


Figure 5 - Rocker Under Bending with Material as Magnesium

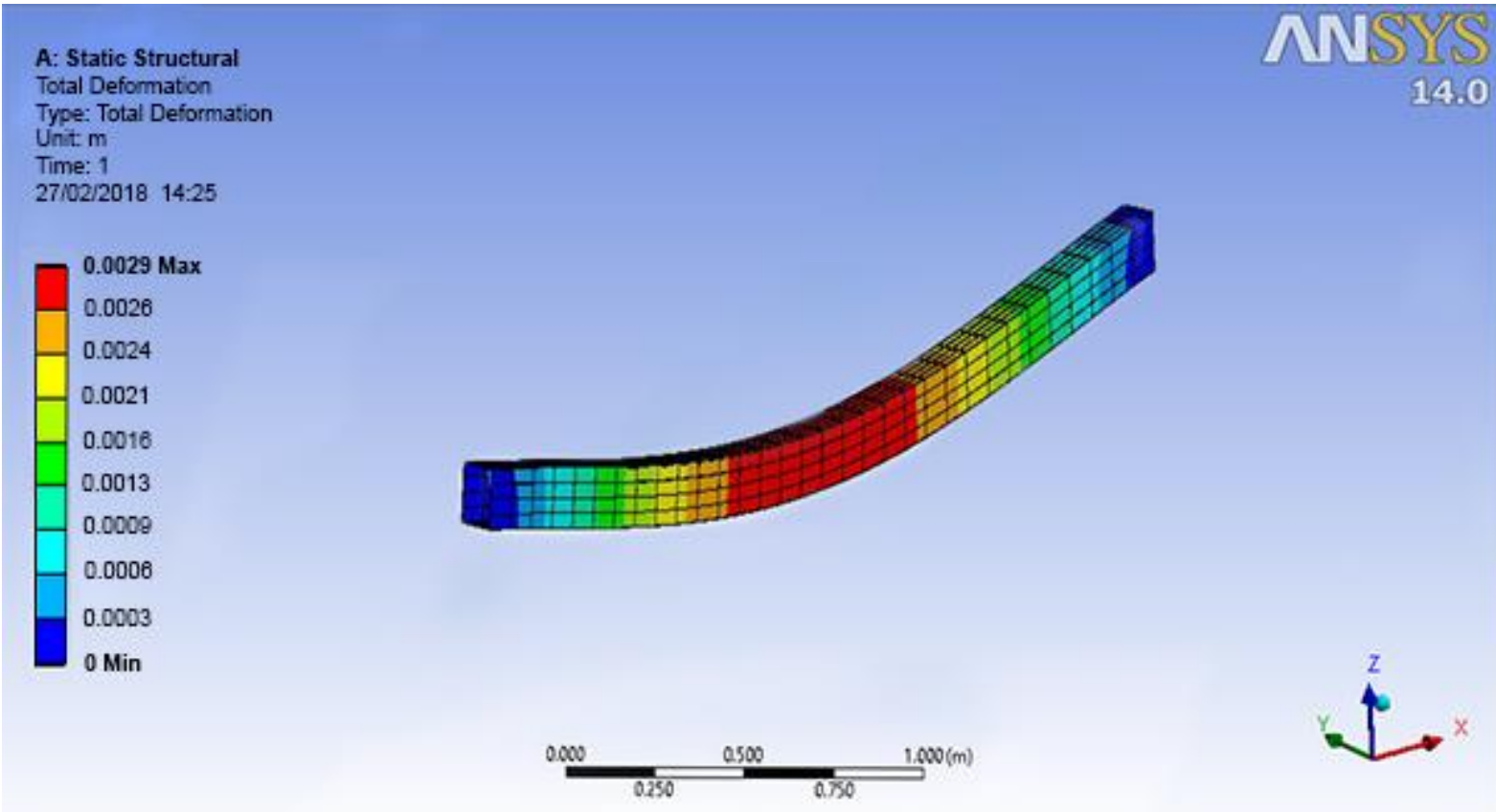


Figure 6 - Rocker Safety Factor with Material as Magnesium

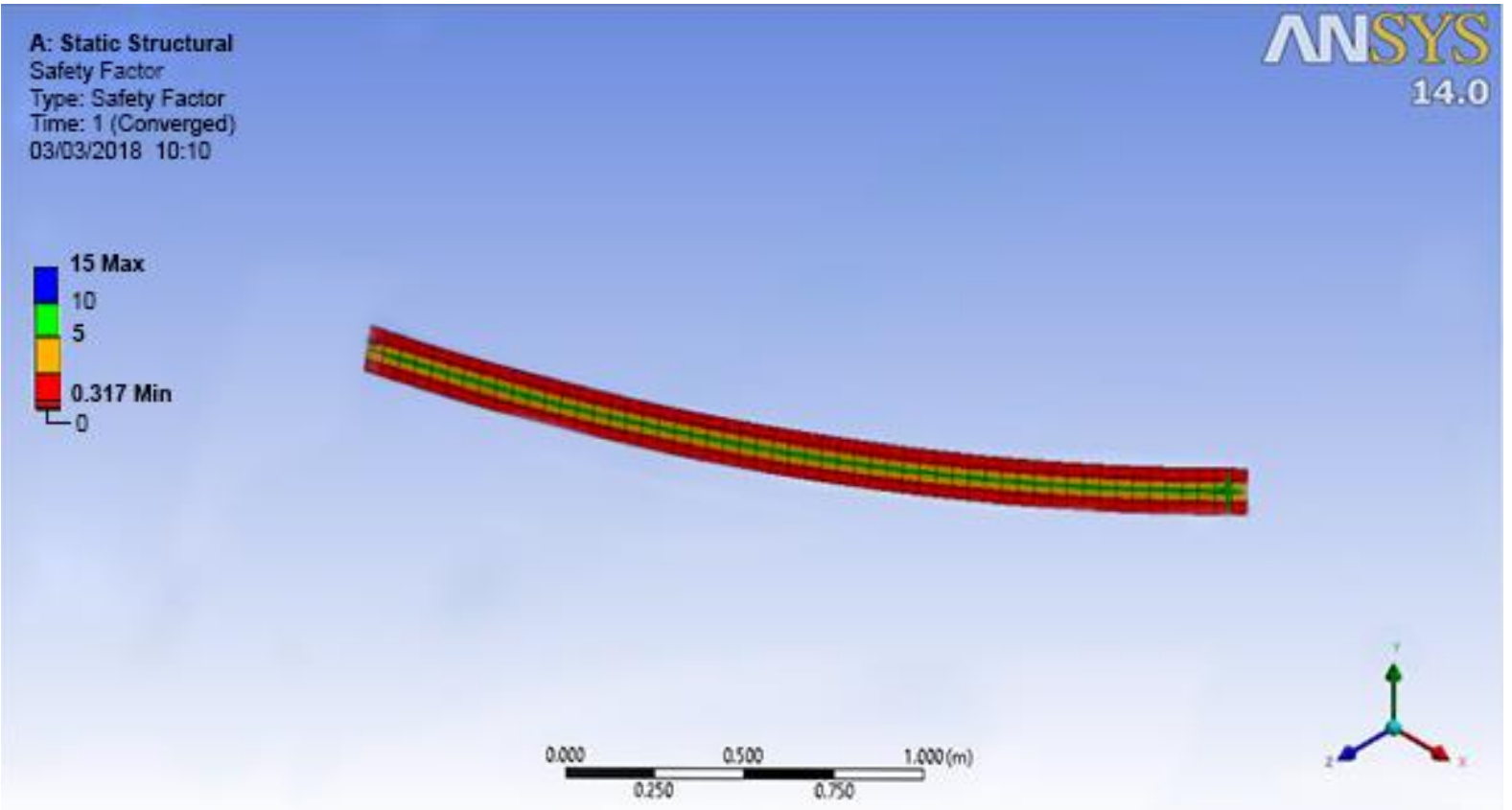


Table 3 - Torsional Calculation Results

\begin{tabular}{cccc}
\hline Material & Steel & Aluminium & Magnesium \\
\hline$\theta_{\text {Rocker }}$ & $2.99 \mathrm{deg}$ & $8.91 \mathrm{deg}$ & $14.48 \mathrm{deg}$ \\
$\mathrm{e}_{\text {Rocker }}$ & $3.77 \mathrm{e}-6 \mathrm{M}^{2}$ & $1.11 \mathrm{e}-5 \mathrm{M}^{2}$ & $1.11 \mathrm{e}-5 \mathrm{M}^{2}$ \\
$\mathrm{e}_{\text {Hinge pillar }}$ & $3.77 \mathrm{e}-6 \mathrm{M}^{2}$ & $1.71 \mathrm{e}-6 \mathrm{M}^{2}$ & $1.71 \mathrm{e}-6 \mathrm{M}^{2}$ \\
$\mathrm{~F}$ & $41.8 \%$ & $68.93 \%$ & $77.42 \%$ \\
$\mathrm{e}_{B E A M^{\mathrm{a}}}$ & $3.60 \times 10^{-6}$ & $1.19 \times 10^{-6}$ & $5.62 \times 10^{-6}$ \\
$\mathrm{e}_{B E A M^{\mathrm{b}}}$ & $3.60 \times 10^{-7}$ & $1.19 \times 10^{-7}$ & $5.6210^{-7}$ \\
$\mathrm{e}_{J O I N T}$ & $2.5 \times 10^{-6}$ & - & - \\
$\Sigma$ & & $70.43 \mathrm{MPa}$ & \\
$\mathrm{K}$ & & $12879.8 \mathrm{Nm} / \mathrm{deg}$ & \\
\hline
\end{tabular}


Figure 7 - Total Deformation on the Side Frame

A: Static Structural
Total Deformation
Type: Total Deformation
Unit: $m$
Time: 1
O1/03/2018 10:19
$\begin{aligned} & 0.00107 \mathrm{Max} \\ & 0.00085 \\ & 0.00083 \\ & 0.00072 \\ & 0.00061 \\ & 0.00048 \\ & 0.00037 \\ & 0.00024 \\ & 0.00012 \\ & 0 \text { Min }\end{aligned}$

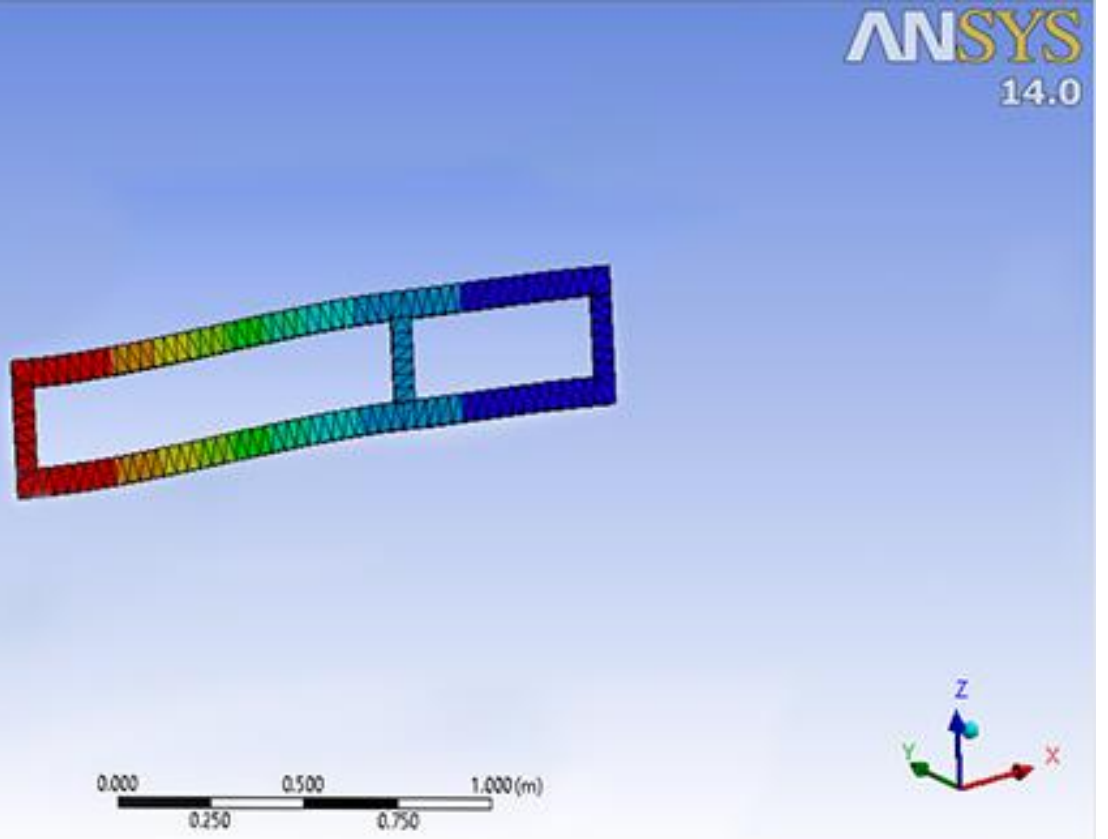


Figure 8 - Torsional Performance of Wikispeed Car Chassis

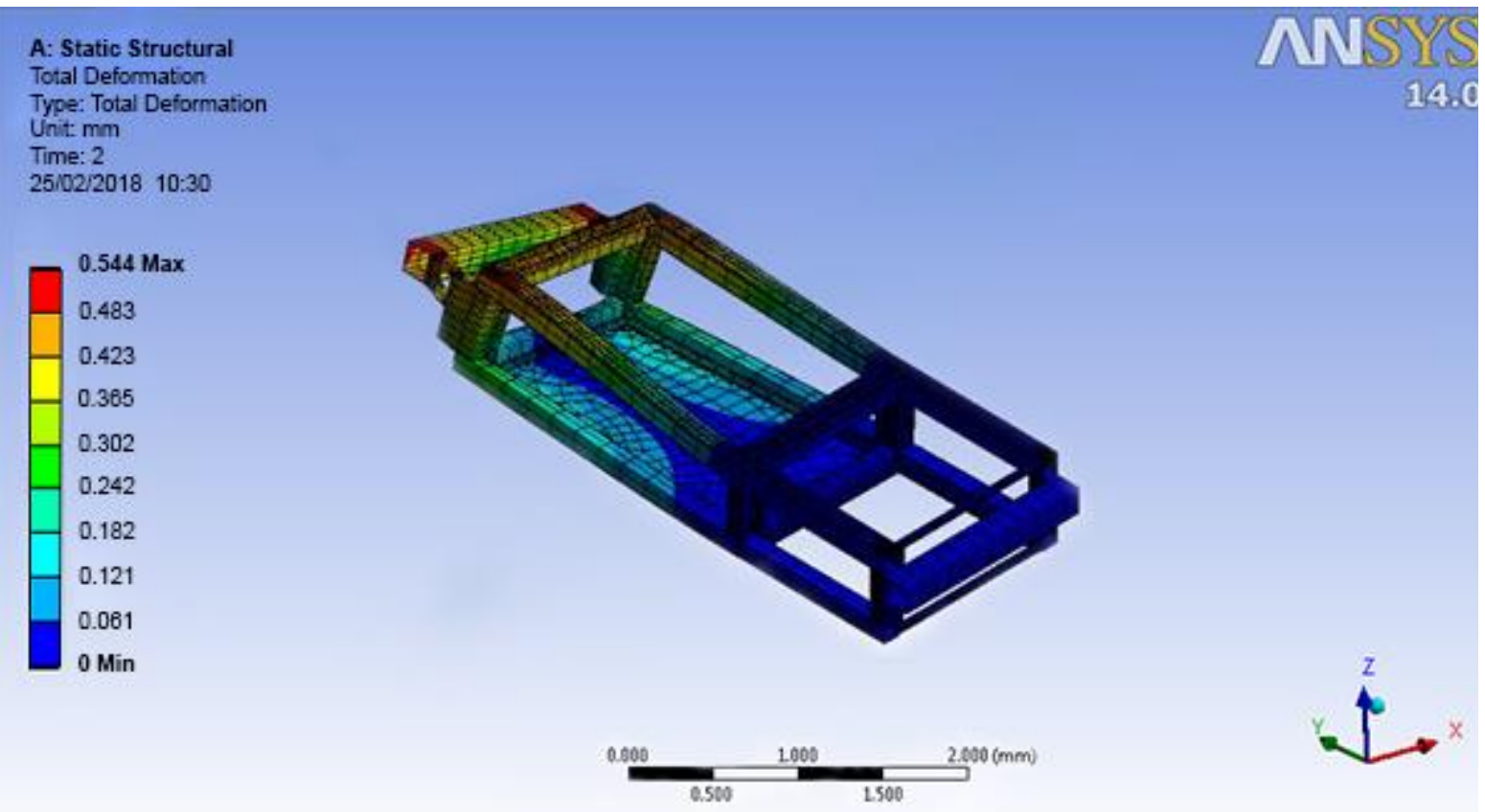


Figure 9 - Chassis of the Wikispeed Car with Yellow Highlighted Rockers

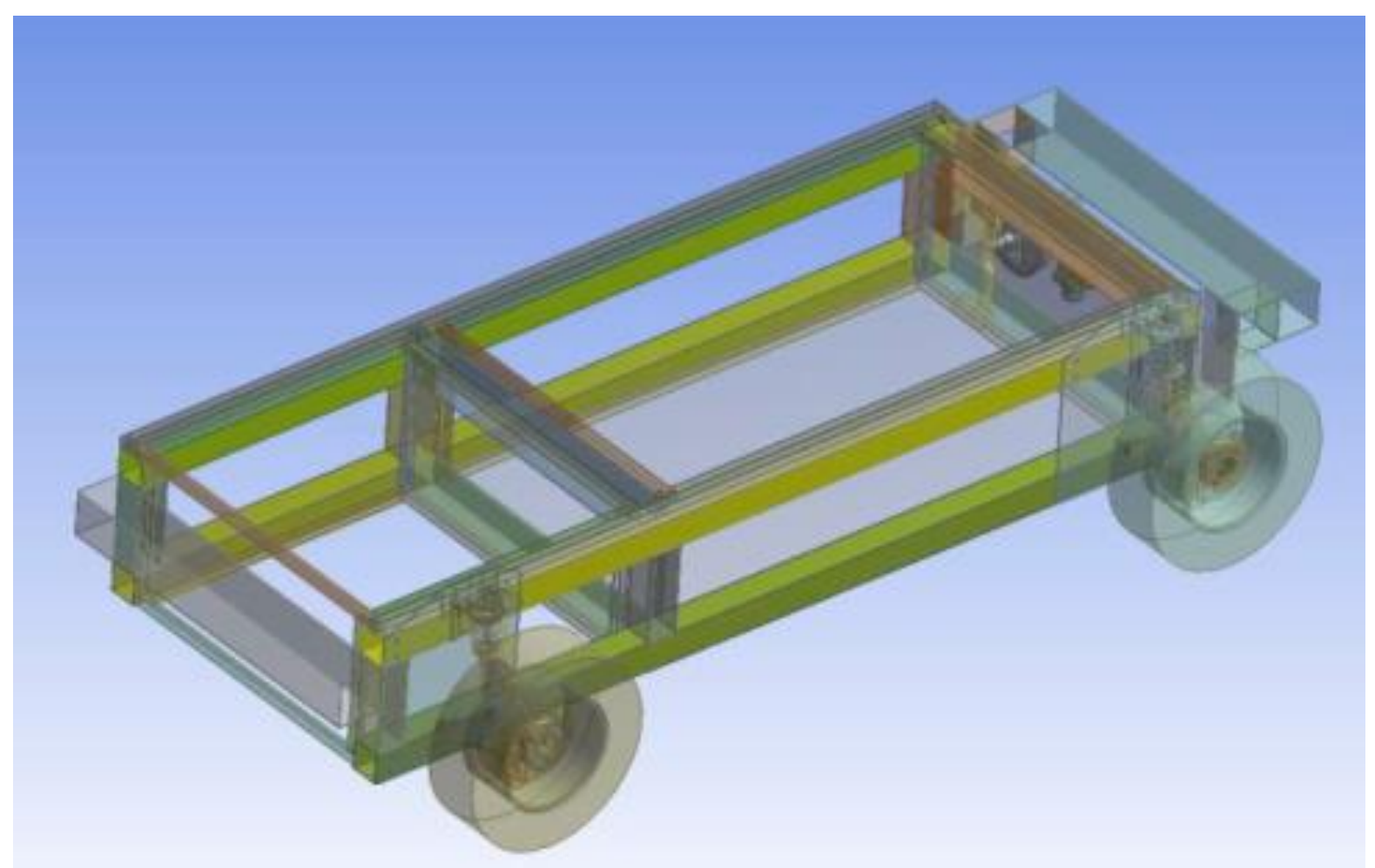


Table 4 - Crashworthiness Calculation Results

\begin{tabular}{cccc}
\hline Calculations & Aluminium & Steel & Magnesium \\
\hline $\mathrm{w}_{1}(\mathrm{~mm})$ & 96.4 & 188 & 135 \\
$\mathrm{w}_{2}(\mathrm{~mm})$ & 76.9 & 110 & 96.1 \\
$\mathrm{P}_{\mathrm{U} 1}(\mathrm{kN})$ & 293 & 540 & 134 \\
$\mathrm{P}_{\mathrm{U} 2}(\mathrm{kN})$ & 234 & 317 & 95.2 \\
$\eta(\%)$ & 98.16 & - & - \\
$\mathrm{F}_{\max }(\mathrm{kN})$ & 193 & 350 & 163 \\
$\mathrm{~F}_{\mathrm{avg}}(\mathrm{kN})$ & 189 & 343 & 160 \\
$\mathrm{CF}_{\mathrm{avg}}(\mathrm{kN})$ & 133 & 129 & 70.4 \\
\hline
\end{tabular}

